\section{Ellagic acid inhibits melanoma growth in vitro}

\author{
J. Daniel Jensen, ${ }^{1}$ Jeffrey H. Dunn, ${ }^{1}$ \\ Yuchun Luo, ${ }^{1}$ Weimin Liu, ${ }^{1}$ \\ Mayumi Fujita,, Robert P. Dellavalle ${ }^{1,2}$ \\ 'Department of Dermatology, School of \\ Medicine, University of Colorado Denver, \\ Aurora; 'Denver Veterans' Affairs Medical \\ Center, Denver, CO, USA
}

\section{Abstract}

Ellagic is a polyphenolic compound with anti-fibrotic and antioxidant properties, and exhibits antitumor properties against various cancer cells in vitro. There are few studies, however, which examine the effects of ellagic acid on melanoma. In the present study, we observe effects of ellagic acid on melanoma cells in vitro. Three metastatic melanoma cell lines (1205Lu, WM852c and A375) were examined to determine the effects of ellagic acid on melanoma cell viability, cell-cycle, apoptosis, NF- $\kappa \beta$ activity, and IL- $1 \beta$ \& IL- 8 secretion. Cell viability assays demonstrated that ellagic acid possesses an inhibitory effect on cell proliferation at concentrations between 25 and $100 \mu \mathrm{M}$. In addition, ellagic acid promoted G1 cell cycle arrest, increased levels of apoptosis and decreased synthesis of IL-1 $\beta$ and IL- 8 in melanoma cells. Ellagic acid also decreased $\mathrm{NF}-\kappa \beta$ activity, suggesting at least one potential mechanism by which ellagic acid may exert its effects in melanoma cells. Our findings support further investigation into prospective roles for ellagic acid as a therapeutic, adjuvant, or preventive agent for melanoma.

\section{Introduction}

Ellagic acid (EA) is a polyphenolic compound found in various types of fruit, including berries, pomegranates, and nuts, and is becoming a popular dietary supplement. It possesses antifibrotic, ${ }^{1,2}$ antiproliferative, ${ }^{3,4}$ and antitumorigenic ${ }^{5,6}$ properties. EA is known to be protective against several types of cancer. EA has been shown to induce apoptosis in human melanoma cells in vitro. ${ }^{7}$

Few studies have investigated the effects of EA on melanoma, however, and the mechanistic action of EA in this setting is not well defined. In vitro studies have shown that EA decreases tyrosinase activity in mouse melanoma cells by chelating the copper tyrosinase cofactor. ${ }^{8}$ We are not aware of any other studies that have defined a mechanism by which EA exerts its effects in melanoma.

The exact mechanism by which EA exerts its effects in other types of cancer is also unclear, but several potential mechanisms have been suggested. EA has been shown to modulate a variety of signaling pathways in cancer cells, including NF- $\kappa \mathrm{B}$, iNOS, and Wnt. Alternative mechanisms through which EA exerts anticancer effects have also been proposed. One group ${ }^{9}$ showed that EA prevented copper and catecholamine transmitter-mediated oxidative DNA damage, thus suggesting a protective role for EA in preventing reactive oxygen species production, lipid peroxidation, and DNA strand breaks. EA has also been shown to induce apoptosis via caspase pathways as well as potentiating trans-retinoic acid-mediated cell-differentiation on human leukemia cell lines. ${ }^{10}$ Another study showed that EA inhibits components of Wnt signaling pathways known to play a pivotal role in human colon carcinogenesis. ${ }^{11}$ Additionally, EA has been shown to reduce hepatic phase I CYP enzymes responsible for converting estrogen to harmful metabolites implicated in mammary tumorigenesis. ${ }^{12}$ EA has been shown to downregulate iNOS, COX-2, TNF- $\alpha$ and IL-6 secretion by inhibiting nuclear factor-kappa $\beta$ (NF- $\kappa \beta$ ) in colon and pancreatic cancers. ${ }^{13}$ Pomegranate fruit extracts (including EA) decrease NF- $\kappa \beta$ expression in UVB-stimulated keratinocytes, decreasing skin tumorigenesis. ${ }^{14,15}$ Here we report on the effect of EA on melanoma cells, including inhibition of the NF- $\kappa$ B pathway.

\section{Materials and Methods}

\section{Tissue culture}

Human metastatic melanoma cell lines (1205LU, WM852c and A375) were cultured in RPMI 1640 medium (GIBCO BRL, Gaithersburg, Maryland, USA) supplemented with 10\% fetal bovine serum (FBS, Gemini Bio-Products, Inc., Woodland, CA, USA) and antibiotics (penicillin $(10,000 \mathrm{IU} / \mathrm{mL})$, streptomycin $(10,000 \mathrm{IU} / \mathrm{mL})$, and amphotericin B (25 microg/mL, Cellgro, Manassas, VA, USA) and were incubated at $37^{\circ} \mathrm{C}$ and $5 \% \mathrm{CO}_{2}$.

\section{Ellagic acid treatment}

EA was obtained from (MP Biochemicals, Solon, OH, USA) and dissolved in sterile DMSO $(5 \mathrm{mM})$ and stored at $-20^{\circ} \mathrm{C}$. Separate, fresh $100 \mu \mathrm{L}$ aliquots of EA were used for each experiment and excess reagent was disposed of according to protocol.

\section{Cell Titer 96 aqueous one solution cell proliferation assay (MTS assay)} for the quantification of cell viability

Experiments were performed according to
Correspondence: Robert P. Dellavalle, Chief Dermatology Service, Department of Veteran Affairs Medical Center, 1055 Clermont Street, Box 165 Denver, C0 80220, USA.

Tel. +1.303 .399 .8020 , ext. 2475 - Fax: +1.303 .393 .4686 . E-mail: robert.dellavalle@ucdenver.edu

Key words: ellagic acid, melanoma, NF-KB, IL-1 $\beta$, IL-8.

Received for publication: 27 August 2011. Accepted for publication: 31 August 2011.

This work is licensed under a Creative Commons Attribution NonCommercial 3.0 License (CC BYNC 3.0).

(C) Copyright J.D. Jensen et al., 2011

Licensee PAGEPress, Italy

Dermatology Reports 2011; 3:e36

doi:10.4081/dr.2011.e36

the manufacturer's instructions (Promega, Madison, WI, USA). Approximately $2.5 \times 10^{3}$ cells were seeded in 96 -well plates and incubated at $37 \mathrm{C}^{\circ}$ and $5 \% \mathrm{CO}_{2}$ for 1 day. EA was added to cells in $0,25,50$ and $100 \mu \mathrm{M}$ concentrations and cells were incubated for 24,48 and $72 \mathrm{~h}$ under previously described conditions. MTS reagent was added to the cells and incubated for $1 \mathrm{~h}$, followed by spectophotometric analysis using an ELX808 Ultra Microplate Reader (Bio-Tek Instruments, Inc., Winooski, VT, USA) and KCjunior v. 1.10 software (BioTek Instruments).

\section{Annexin $\mathrm{V}$ apoptosis detection assay}

An annexin-FITC apoptosis detection kit (BD Biosciences Pharmingen, San Diego, CA, USA) was used, following the manufacturer's instructions; $4 \times 10^{5}$ cells were seeded in $10 \mathrm{~cm}$ plates and incubated for $24 \mathrm{~h}$. Cells were treated with ellagic acid in DMSO at 0, 25, 50 and $100 \mu \mathrm{M}$ concentrations. Cells were incubated as previously described for $72 \mathrm{~h}$ and stained with Annexin V antibodies and PI. Samples were analyzed by the FACS core using a Beckman Coulter FC500 flow cytometer (Beckman Coulter). Apoptotic cells were defined as being positive for Annexin $\mathrm{V}$.

\section{Cell cycle analysis}

$4 \times 10^{5}$ cells were seeded on $10 \mathrm{~cm}$ tissue culture dish and incubated overnight prior to treatment with EA. Cells were treated with 0 or $50 \mu \mathrm{M}$ EA and incubated at $37^{\circ} \mathrm{C}$ for $48 \mathrm{~h}$. Cells were then detached from the plate, stained with propidium iodide (PI) and allowed to incubate overnight at $4^{\circ} \mathrm{C}$. Cells were then analyzed with by the University of Colorado Denver Fluorescent Activated Cell Sorting (FACS) core using a Beckman Coulter FC500 flow cytometer (Beckman Coulter Inc, Brea, CA, USA). 


\section{NF- $\kappa \beta$ luciferase reporter assay}

$2.5 \times 10^{3}$ cells were seeded into 24 -well plates and were transfected after $12 \mathrm{~h}$ of incubation. Transfection with pNFK $\beta$-MetLuc2 Reporter Vector (Clontech, Mountain View, CA, USA) was performed according to protocol described by the Lipofectamine 2000 kit (Invitrogen, Carlsbad, CA, USA). Cells were then treated with $0,25,50$ and $100 \mu \mathrm{M}$ EA and incubated for 24 or $48 \mathrm{~h}$. Luminescence was then measured with a luminometer (Promega, Madison, WI, USA).

\section{Measurement of gene expression (IL-1 $\beta$, IL-8)}

1205Lu metastatic melanoma cells were seeded and incubated for $24 \mathrm{~h}$ under previously described conditions. Cells were then treated with 0 or $50 \mu \mathrm{M}$ EA for $48 \mathrm{~h}$. Cells were detached from culture dishes and RNA was extracted from treated and untreated cells using the RNAqueous-Micro kit (Ambion, Austin, TX, USA), and subsequently reverse transcribed using random primers and MMLV reverse transcriptase (Promega, Madison, WI, USA). Realtime quantitative reserve transcription-PCR (qRT-PCR) was performed with Power SYBR Green PCR Master Mix (Applied Biosystems, Foster City, CA, USA) on the MX3000P PCR system (Strategene, La Jolla, CA, USA). Primers were designed to generate a PCR product of 50 to $150 \mathrm{bp}$. Thermal cycling conditions were $95^{\circ} \mathrm{C}$ for 10 min followed by 42 cycles of $15 \mathrm{~s}$ at $95^{\circ} \mathrm{C}, 1$ min at $60^{\circ} \mathrm{C}$. GAPDH was used as a control to normalize the results.

\section{Statistical analysis}

The viabilities of each treated cell line were compared to control was evaluated using a Student's t-test. Values of $\mathrm{P}<0.05$ were considered to be statistically significant.

\section{Results}

Melanoma cell viability is inhibited by Ellagic acid

Cells were incubated with different concentrations of EA for 24, 48, and $72 \mathrm{~h}$ and cell viability was measured using the MTS assay (Figure 1A, B). Inhibition of cell growth was detected as early as $24 \mathrm{~h}$ at 50 and $100 \mu \mathrm{M}$ concentrations EA for 1205Lu cells $(\mathrm{P}<0.01$ and $\mathrm{P}<0.05$, respectively) and at 25,50 , and $100 \mu \mathrm{M}$ concentrations EA for WM852c cells $(\mathrm{P}<0.05, \mathrm{P}<0.05$ and $\mathrm{P}$ $<0.01$, respectively). EA continued to inhibit cell growth for a $72 \mathrm{~h}$ period at 25,50 and $100 \mu \mathrm{M}$ concentrations $(\mathrm{P}<0.05, \mathrm{P}<0.01$ or $\mathrm{P}<0.001$ for all data points measured).

\section{Ellagic acid induces apoptosis in melanoma cell lines}

Decreased viability is caused by cell death and/or decreased cell growth. In order to determine if EA exerted a proapoptotic effect in metastatic melanoma, three cell lines (1205LU, WM852c, A375) were incubated in 25, 50 and $100 \mu \mathrm{M}$ concentrations of EA for $72 \mathrm{~h}$ (Figure 2A). After staining for the apoptotic marker Annexin V, cell lines were sorted with flow cytometry. 1205LU cells demonstrated increased apoptosis when compared to controls at 50 and $100 \mu \mathrm{M}(\mathrm{P}<0.01$ and $0<0.001$, respectively). Furthermore, both WM852c and A375 cell lines had increased levels of apoptotic cells at $100 \mu \mathrm{M}$ concentrations $\mathrm{EA}(\mathrm{P}<0.05)$. In general, there was a trend toward increased apoptosis with increasing concentrations of EA.

\section{Ellagic acid induced G1 cell cycle arrest}

In order to determine if EA inhibited cell proliferation via cell cycle arrest, WM852c cells were incubated for $48 \mathrm{~h}$ in $50 \mu \mathrm{M}$ EA. After staining, cells were sorted according to the phase of their cell cycle (Figure 2B). Cell cycle analysis of WM852c cells in G1 phase suggested disruption of cellular replication $(\mathrm{P}<0.01)$, suggesting that EA inhibited melanoma cell proliferation via G1 cell cycle arrest.

\section{Ellagic acid downregulates NF- $\kappa \beta$}

activity in metastatic melanoma cells

Several studies reported that EA modulates the NF- $\kappa \beta$ pathway in cancer cells, therefore NF$\kappa \beta$ activity and expression in EA-treated cells was compared to untreated controls (Figure 3A, B). At $24 \mathrm{~h}, \mathrm{NF}-\kappa \beta$ expression was decreased in both cell lines for all concentrations tested except for $25 \mu \mathrm{M}$ in $1205 \mathrm{Lu}$ (for $1205 \mathrm{Lu}$, $\mathrm{P}<0.001$ for 50 and $100 \mu \mathrm{M}$ concentrations; for WM852, $\mathrm{P}<0.01$ for $50 \mu \mathrm{M}, \mathrm{P}<0.001$ for 25 and $100 \mu \mathrm{M} \mathrm{EA})$. At $48 \mathrm{~h}$, there was decreased expression of NF- $\kappa \beta$ with EA treatment at 25,50 and $100 \mu \mathrm{M}$ (for $1205 \mathrm{Lu}, \mathrm{P}<0.01$ for all concentrations; for WM852, $\mathrm{P}<0.05, \mathrm{P}<0.01$ and $\mathrm{P}<0.01$ for 25, 50 and $100 \mu \mathrm{M} \mathrm{EA}$, respectively).

\section{Ellagic acid decreases synthesis of} IL-1 $\beta$ and IL-8 in metastatic melanoma cells

Downstream effectors of the NF- $\kappa \beta$ pathway which control cell proliferation and apoptosis were measured using quantitative RT-PCR. As indicated in Figure 4, mRNA coding for IL-1 $\beta$ and IL-8 8 were significantly decreased $(\mathrm{P}<0.05)$ by treatment with $\mathrm{EA}$.

\section{Discussion}

This study suggests that EA induces apoptosis and G1 cell cycle arrest in melanoma cells at in vitro concentrations between 25 and 100 $\mu \mathrm{M}$. Inhibition of the NF- $\kappa \beta$ pathway was also shown to be a potential mechanism by which EA exerts its antiproliferative effects. The NF$\kappa \beta$ pathway frequently plays a central role in the pathogenesis of many types of cancer, and therapeutic modalities which target the NF- $\kappa \beta$ pathway and its downstream intermediates are under investigation.

Dysregulation of the NF- $\kappa \beta$ pathway in the

A

Cell Viability- WM852c
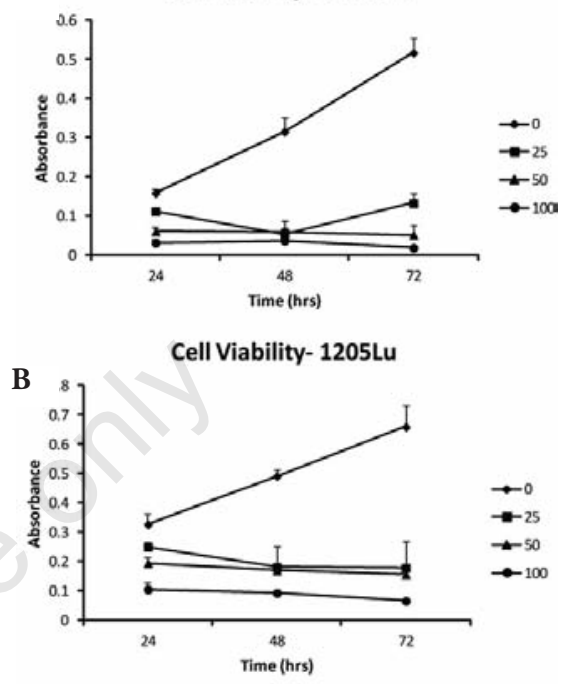

Figure 1. Cell growth over time with different concentrations of EA. A) WM852c and B) $1205 \mathrm{Lu}$ cells were incubated with different concentrations of EA for 24, 48, and $72 \mathrm{~h}$ and cell viability was measured using MTS assay.

A \% Apoptotic Cells with EA Treatment

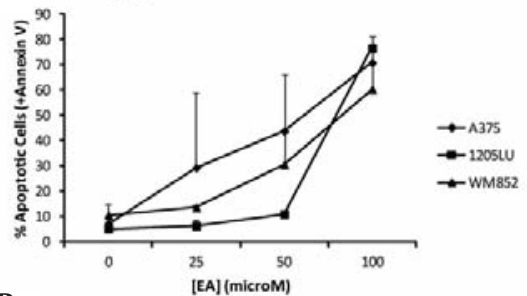

B

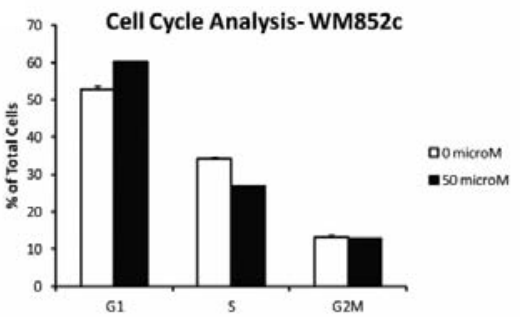

Figure 2. A) Apoptotic cells at $72 \mathrm{~h}$. Three cell lines (1205Lu, WM852c, A375) were incubated in 25,50 and $100 \mu \mathrm{M}$ concentrations of EA for $72 \mathrm{~h}$. After staining for the apoptotic marker Annexin V, cell lines were then sorted with flow cytometry. B) Cell cycle analysis. WM852c cells were incubated for $48 \mathrm{~h}$ in $50 \mu \mathrm{M}$ EA. After staining, cells were sorted according to the phase of their cell cycle. 
setting of melanoma, a particularly treatmentresistant malignancy, is very common. Inhibition of NF- $\kappa \beta$ has been explored as a potential therapeutic strategy against melanoma with positive results. ${ }^{16}$ For example, $\mathrm{NF}-\kappa \beta$ upregulation has been shown to pro-

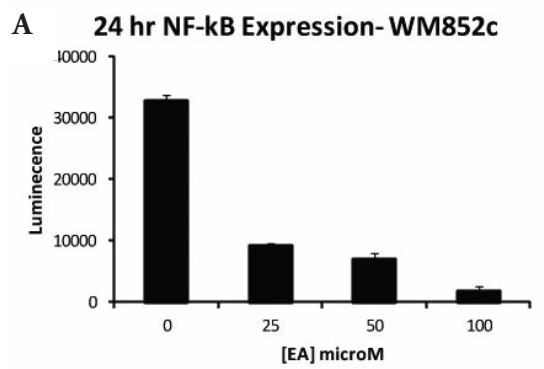

B

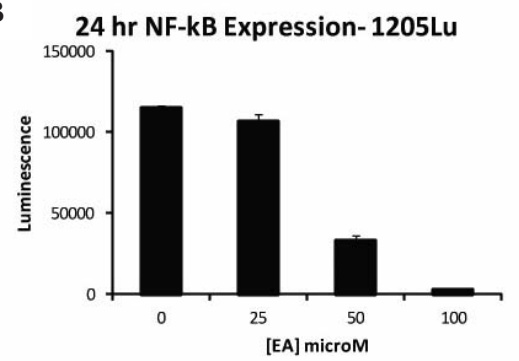

Figure 3. Expression of NF- $\kappa \beta$ after EA treatment. A plasmid containing a luciferase reporter gene under the control of NF- $\kappa \beta$ was transfected into WM852c (A) and 1205LU cells (B) and measured after 24 hours incubation.

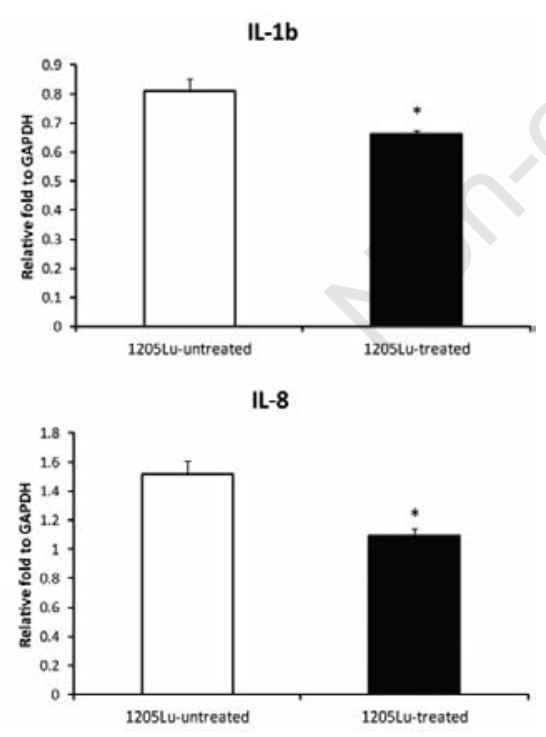

Figure 4. Expression of IL-1 $\beta$ and IL-8 cytokines after EA treatment. Metastatic melanoma cells were seeded and incubated for $24 \mathrm{~h}$. Cells were then treated with 0 or $50 \mu \mathrm{M}$ EA for $48 \mathrm{~h}$. RNA was extracted from treated and untreated cells and measured by $\mathrm{qRT}$-PCR. GAPDH was used as a control. ${ }^{*} \mathbf{P}<\mathbf{0 . 0 5}$ mote angiogenesis in melanoma, ${ }^{17}$ a key mechanism in tumor growth and maintenance. NF- $\kappa \beta$ also increases the rate of melanoma metastasis. ${ }^{18}$ Conversely, suppression of NF- $\kappa \beta$ attenuates the invasive potential of tumors. ${ }^{19}$ Further evidence of the importance of the NF- $\kappa \beta$ pathway in melanoma is that ablation of an upstream effector of the NF$\kappa \beta$ pathway, Ikappa $\beta$ kinase beta (IKK $\beta$ ), inhibits melanoma tumorigenesis ${ }^{20}$ and increased susceptibility to chemotherapy. ${ }^{21}$ Furthermore, $\mathrm{p} 53$ is inversely related to NF- $\kappa \beta$ expression, ${ }^{22}$ and p53-mediated G1 cell cycle arrest may result from downregulation of NF$\kappa \beta$ in cancer cell. ${ }^{4}$

These findings support a potential role for EA as a therapeutic, adjuvant, or preventive agent for melanoma. Future work, however, should address the limitations of this study. While our data shows some evidence that EA treatment is associated with increased cellcycle arrest and apoptosis, as well as decreased melanoma cell viability and NF- $\kappa \beta$ activity, these results were not obtained in the presence of a vehicle control. Follow up work is therefore indicated to determine if EA specifically inhibits melanoma through the pathways observed in this study. Furthermore, the concentrations of EA used in our study are higher than levels that are generally sustainable by normal consumption of EA-containing foods (typically ranging from 5-15 $\mu \mathrm{M} .{ }^{23,24}$ While the use of higher doses of EA as an adjuvant to other therapies may prove to be of some benefit to patients it is not clear from these results if EA may exert therapeutic benefits at practical dietary doses.

\section{References}

1. Thresiamma KC, Kuttan R. Inhibition of liver fibrosis by ellagic acid. Indian $\mathrm{J}$ Physiol Pharmacol 1996;40:363-6.

2. Devipriya N, Sudheer AR, Srinivasan M, Menon VP. Effect of Ellagic acid, a plant polyphenol, on fibrotic markers (MMPs and TIMPs) during alcohol-induced hepatotoxicity. Toxicol Mech Methods 2007;17:349-56.

3. Losso JN, Bansode RR, Trappey A 2nd, et al. In vitro anti-proliferative activities of ellagic acid. J Nutr Biochem 2004;15:6728.

4. Narayanan BA, Geoffroy 0, Willingham MC, et al. p53/p21(WAF1/CIP1) expression and its possible role in Gl arrest and apoptosis in ellagic acid treated cancer cells. Cancer Lett 1999;136:215-21.

5. Mukhtar H, Das M, Khan WA, et al. Exceptional activity of tannic acid among naturally occurring plant phenols in protecting against 7,12 dimethylbenz(a)- anthracene-, benzo(a)pyrene-, 3-methylcholanthrene-, and N-methyl-N-nitrosourea-induced skin tumorigenesis in mice. Cancer Res 1988;48:2361-5.

6. Kowalczyk MC, Kowalczyk P, Tolstykh 0, et al. Synergistic effects of combined phytochemicals and skin cancer prevention in SENCAR mice. Cancer Prev Res (Phila) 2010;3:170-8.

7. Kim S, Liu Y, Gaber MW, et al. Development of chitosan-ellagic acid films as a local drug delivery system to induce apoptotic death of human melanoma cells. J Biomed Mater Res B Appl Biomater 2009; 90:145-55.

8. Shimogaki H, Tanaka Y, Tamai H, Masuda M. In vitro and in vivo evaluation of ellagic acid on melanogenesis inhibition. Int $\mathbf{J}$ Cosmet Sci 2000;22:291-303.

9. Spencer WA, Jeyabalan J, Kichambre S, Gupta RC. Oxidatively generated DNA damage after $\mathrm{Cu}$ (II) catalysis of dopamine and related catecholamine neurotransmitters and neurotoxins: Role of reactive $0 x y-$ gen species. Free Radic Biol Med 2010; 50:139-47.

10. Hagiwara Y, Kasukabe T, Kaneko Y, et al. Ellagic acid, a natural polyphenolic compound, induces apoptosis and potentiates retinoic acid-induced differentiation of human leukemia HL-60 cells. Int $\mathrm{J}$ Hematol 2010;92:136-43.

11. Sharma M, Li L, Celver J, et al. Effects of fruit ellagitannin extracts, ellagic acid, and their colonic metabolite, urolithin A, on Wnt signaling. J Agric Food Chem 2009; 58:3965-9.

12. Aiyer H, Gupta RC. Berries and ellagic acid prevent estrogen-induced mammary tumorigenesis by modulating enzymes of estrogen metabolism. Cancer Prev Res (Phila) 2010;3:727-37.

13. Umesalma S, Sudhandiran G. Differential inhibitory effects of the polyphenol ellagic acid on inflammatory mediators NFkappaB, iNOS, COX-2, TNF-alpha, and IL-6 in 1,2-dimethylhydrazine-induced rat colon carcinogenesis. Basic Clin Pharmacol Toxicol 2010;107:650-5.

14. Afaq F, Malik A, Syed D, et al. Pomegranate fruit extract modulates UV-B-mediated phosphorylation of mitogen-activated protein kinases and activation of nuclear factor kappa B in normal human epidermal keratinocytes paragraph sign. Photochem Photobiol 2005;81:38-45.

15. Afaq F, Saleem M, Krueger CG, et al. Anthocyanin- and hydrolyzable tannin-rich pomegranate fruit extract modulates MAPK and NF-kappaB pathways and inhibits skin tumorigenesis in CD-1 mice. Int J Cancer 2005;113:423-33.

16. Czyz M, Lesiak-Mieczkowska K, Koprowska K, et al. Cell context-dependent activ- 
ities of parthenolide in primary and metastatic melanoma cells. Br J Pharmacol 2010;160:1144-57.

17. Karst AM, Gao K, Nelson CC, Li G. Nuclear factor kappa B subunit p50 promotes melanoma angiogenesis by upregulating interleukin-6 expression. Int $\mathrm{J}$ Cancer 2009;124:494-501.

18. Wu FH, Yuan Y, Li D, et al. Endothelial cellexpressed Tim-3 facilitates metastasis of melanoma cells by activating the NFkappaB pathway. Oncol Rep 2010;24:693-9.

19. Kim A, Kim MJ, Yang Y, et al. Suppression of NF-kappaB activity by NDRG2 expression attenuates the invasive potential of highly malignant tumor cells. Carcinogenesis 2009;30:927-36.

20. Yang J, Splittgerber R, Yull FE, et al. Conditional ablation of Ikkb inhibits melanoma tumor development in mice. J Clin Invest 2010;120:2563-74.

21. Amschler K, Schon MP, Pletz N, et al. NFkappaB inhibition through proteasome inhibition or IKKbeta blockade increases the susceptibility of melanoma cells to cytostatic treatment through distinct pathways. J Invest Dermatol 2010;130: 1073-86.

22. Rasmussen MK, Iversen L, Johansen C, et al. IL-8 and p53 are inversely regulated through JNK, p38 and NF-kappaB p65 in HepG2 cells during an inflammatory response. Inflamm Res 2008;57:329-39.

23. Mertens-Talcott SU, Jilma-Stohlawetz P, Rios J, et al. Absorption, metabolism, and antioxidant effects of pomegranate (Punica granatum l.) polyphenols after ingestion of a standardized extract in healthy human volunteers. J Agric Food Chem 2006;54:8956-61.

24. Seeram NP, Lee R, Heber D. Bioavailability of ellagic acid in human plasma after consumption of ellagitannins from pomegranate (Punica granatum L.) juice. Clin Chim Acta 2004;348:63-8. 